\title{
Health Care for Cattles Using Telecommunication
}

\author{
Joshi D.A, PIET; Gharge A.P, PIET; Gohil R., AMUL
}

\begin{abstract}
Health care for cattle's using telecommunication is a concept that has evolved to address the issues of call routing from the current healthcare dynamics. The aim to decongest to reduce costs, for both Companies and farmers, and making healthcare available to all who need it is met.

The action expected from the valerians as a result of such monitoring is to make clinical decisions on whether the patient requires:

* Immediate treatments

* Urgent doctor visit

* Continued monitoring

The judgment on which patients can be put into a continuous monitoring mode Instead of frequents visits by veterinary doctors.
\end{abstract}

\section{Introduction}

People live in rural area cannot get primary information about the primary treatment of the diseases for their cattle, how to take care of cattle in different season and they face difficulties in communication about the booking visit of veterinary doctor.

Sometimes the care taker of the cattle are not aware of primary treatment their cattle, how to take care of cattle in different season, visit booking of veterinary doctor.

Due to this problem now we are develop new concept of health care for animals.

This services are to be Implemented to reduce the Emergence congestion, Cattle travel, working towards prevention and cure rather than treatment and sickness and overall healthcare costs.

The aim to decongest to reduce costs, for both Companies and farmers, and making healthcare available to all who need it is met.

The infrastructure is an all-inclusive term that encompasses a number of high-tech applications that involve providing remote care for cattle.

The action expected from the valerians as a result of such monitoring is to make a clinical decision on whether the patient requires:

* Immediate treatments

* Urgent doctor visit

\# Continued monitoring

The judgment on which patients can be put into a continuous remote monitoring mode Instead of frequents visits by veterinary doctors

\section{Voice over Internet}

Voice over Internet Protocol (VoIP) is a methodology and group of technologies for the delivery of voice communications and multimedia sessions over Internet Protocol(IP) networks, such as the Internet. Other terms commonly associated with VoIP are IP telephony, Internet telephony, voice over broadband (VoBB), broadband telephony, IP communications, and broadband phone service.

\section{SIP: Session Initiation Protocol}

SIP, the session initiation protocol, is the IETF protocol for VOIP and other text and multimedia sessions, like instant messaging, video, online games and other services.

Abstract from the RFC 3261 (formatted and explained version) - SIP: Session Initiation Protocol

This document describes Session Initiation Protocol (SIP), an application-layer control (signaling) protocol for creating, modifying, and terminating sessions with one or more participants. These sessions include Internet telephone calls, multimedia distribution, and multimedia conferences

SIP is a text-based protocol that uses UTF-8 encoding

SIP uses port 5060 both for UDP and TCP. SIP may use other transports

SIP offers all potentialities of the common Internet Telephony features like: call or media transfer

call conference

call hold 
Since SIP is a flexible protocol, it is possible to add more features and keep downward interoperability. SIP also does suffer from NAT or firewall restrictions. (Refer to NAT and VOIP). SIP can be regarded as the enabler protocol for telephony and voice over IP (VoIP) services. The following features of SIP play a major role in the enablement of IP telephony and VoIP:

\section{Problem Solution}

Develop a call center headquarter at a single place which provide primary care information by telephonic communication and connect the server to the nearby location from area of the caller. The remote Cattle monitoring services are to be implemented to reduce the following,

The Emergence congestion

Cattle travel

Working towards prevention and cure rather than treatment and sickness

Overall healthcare costs

Emergence congestion we use packet priority concept for cattles, also we use GPRS for bi-direction.

Hardware \& Software Component

Hardware:

1. PRI Line with Toll Free Circuit,

2. Database Server,

3. Application Server,

Software:

4. Dialer with Telephone interface.

1. Astreak Dialer Software (Linux) MySQL Database,PHP

2. Application Server, ASP.Net,

3. Database Server, Microsoft Sql Database.

Experiment

To resolve problem of delay in cattle treatment we had plan to set up call center the flow of process is show in following chart.

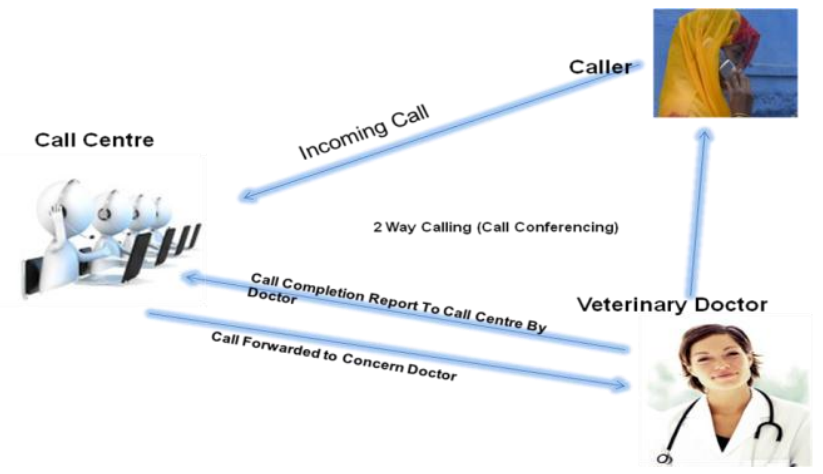

Figure 1flow diagram of calling process

As we can see the flow of process in the chart, framer is calling to the call center agent on that time call pickup, call pause ,call transfer all process done by Go auto dial software after that call booking process completed by Asp.net software after that call center agent forward this report to the allocators and allocator manage whole system, those message should be reached to the doctor tablet which is forward by agent, then doctor give reply to the call center agent ,in any case if emergency require doctor directly contact to the caller. The history record of the animal treatment is stored in the server which displayed to the authorized person on the demand which will be useful in future treatment. 


\section{Results}

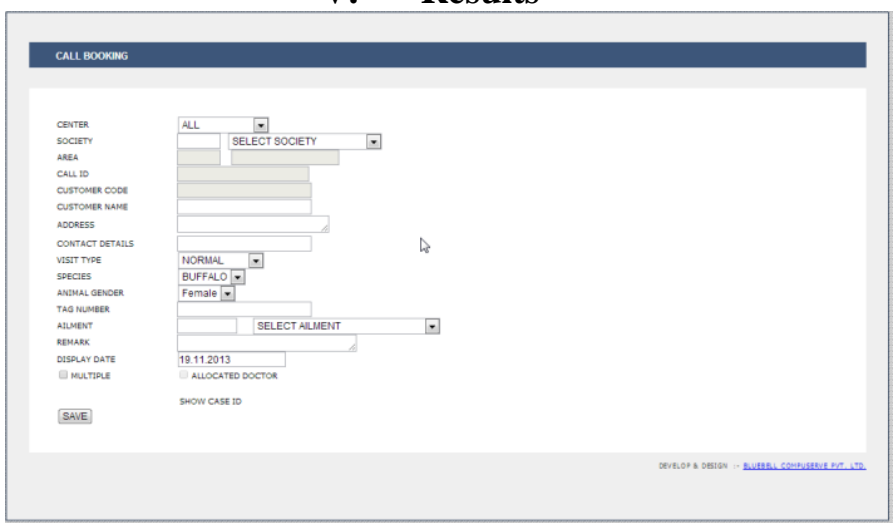

Figure 2. Result for call booking

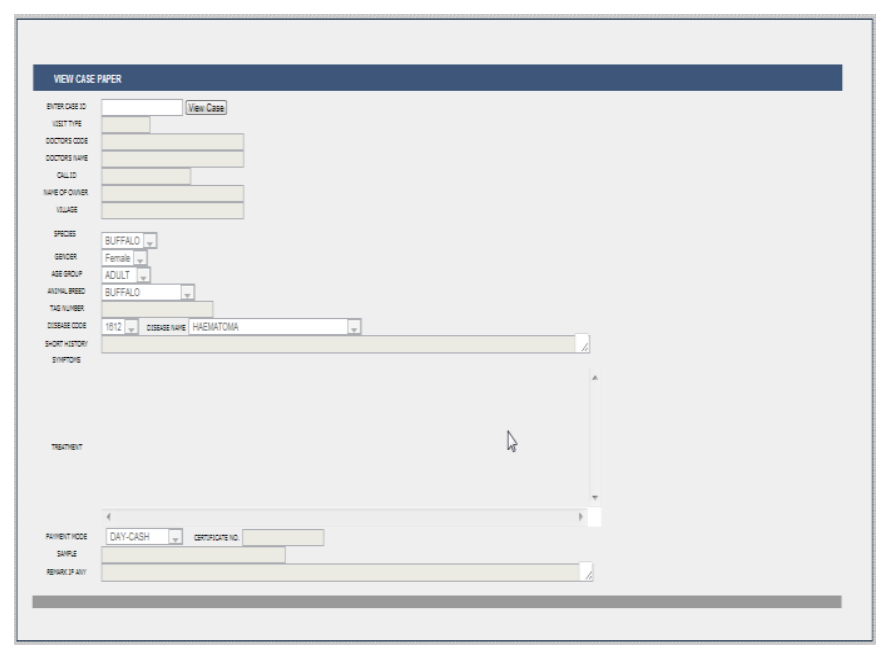

Figure 3. Display of case paper
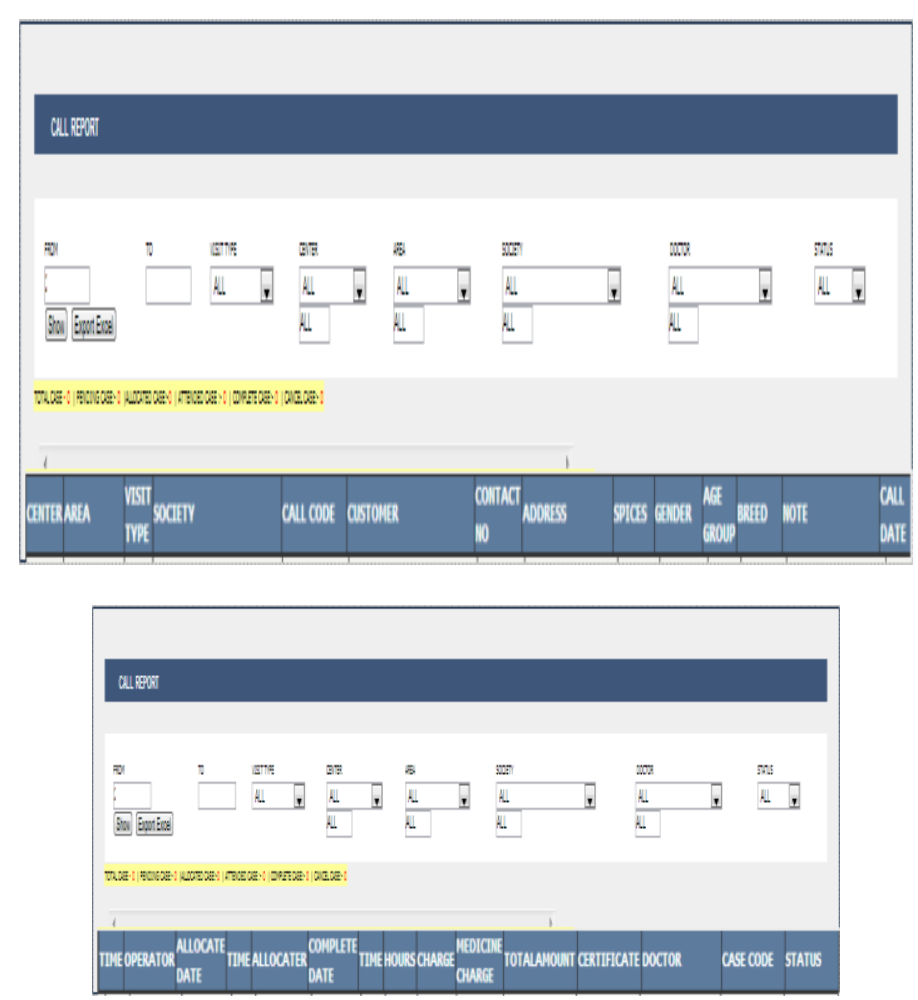

Figure 4. call report 


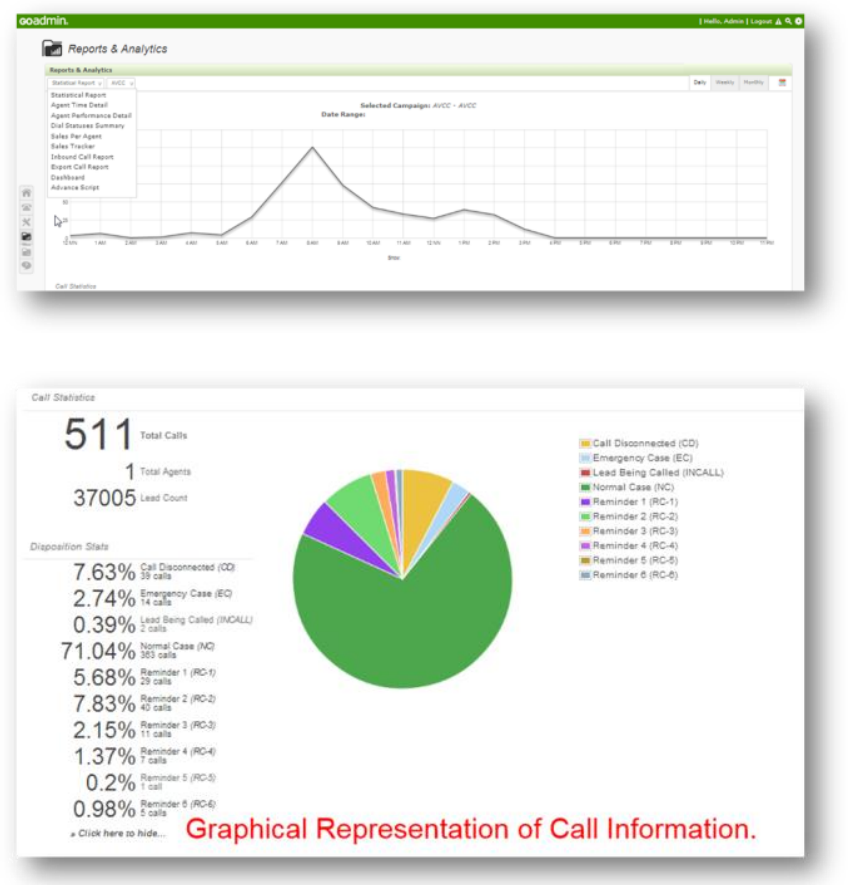

Figure 5. Research analytics

\section{Conclusion}

The Cattle monitoring services are to be implemented to reduce the Emergence congestion, Cattle travel, working towards prevention and cure rather than treatment and sickness and overall healthcare costs.

\section{Future work}

In the process of Cattle monitoring services we face a need of voice logger of higher data storage capacity which can be helpful as a backup plan for the data protection in case of server crash and limited capacity of asterisk data storage server.

\section{Acknowledgments}

We are thankful to IOSR Journal for the support to develop this document.

\section{References}

[1] Dr. Akram A., Prof. Al-Mashouq k., Dr. Al-Hokail z Remote Monitoring Using Wireless Cellular Networks; (IJACSA,Vol. 4, No. 2,2012

[2] Mashael S.; Mznah A; Diabetes Monitoring System Using Mobile Computing Technologies; IJDIWC Vol. 4, No 2,79-83 The Society of Digital Information and Wireless Communications, 2013

[3] Ahmed B., Abdulrahman H.; Rizwan M.; Qureshi J. and Khan A; Novel Component-Based Development model For Sip-Based Mobile Application; IJSEA, Vol.3, No.1, January 2012

[4] www.convergencetechnologycenter.org

[5] http://www.ibef.org/industry/healthcare-india.aspx

[6] http://goautodial.org/

[7] http:a//www.nda.agric.za/docs/Infopaks/diseases.html

[8] http://www.excitingip.com/687/what-is-a-pri-line-what-are-the-advantages-and-limitations-of-pri-circuits/

[9] http://www.webopedia.com/TERM/D/database_server.html

[10] http://www.keithjbrown.co.uk/vworks/images/mysql.png 